\section{Cerebral Perfusion Pressure}

Gary Tye ${ }^{1}$ and John Brown ${ }^{2}$

${ }^{1}$ Neurosurgery, Virginia Commonwealth

University, Richmond, VA, USA

${ }^{2}$ Medical College of Georgia, Augusta, GA, USA

\section{Definition}

Cerebral perfusion pressure (CPP) is the net pressure of flow of the blood to the brain, which is the difference between the mean arterial pressure (MAP) and the intracranial pressure (ICP).

\section{Cross-References}

- Cerebral Blood Flow

- Intracranial Pressure

\section{References and Readings}

Diringer, M. N., \& Axelrod, Y. (2007). Hemodynamic manipulation in the neuro-intensive care unit: Cerebral perfusion pressure therapy in head injury and hemodynamic augmentation for cerebral vasospasm. Current Opinion in Critical Care, 13(2), 156-162.

Wright, W. L. (2007). Multimodal monitoring in the ICU: When could it be useful? Journal of the Neurological Sciences, 261(1-2), 10-15. 